\title{
ANALYSIS OF SITES USED AS A SOURCE OF RESEARCH IN HIGHER SCHOOL OF BIOCHEMISTRY
}

\author{
${ }^{1}$ Chagas, J. G.; ${ }^{1}$ Lima, R.M., ${ }^{1}$ Azevedo, M. P. S., ${ }^{2}$ Fernandes, K.V.S. \\ ${ }^{1}$ Instituto Federal Fluminense, IFF Campus Campos-Centro \\ ${ }^{2}$ Universidade Estadual do Norte Fluminense
}

The technological breakthrough noticed in the past few years, promoted an increase of the knowledge production within the use of the internet leading the population to the easy access to the information. Therefore, the control of quality of the information given in the internet is not able to check the all the information in it, which demands the users an extra expertise. This research has the aim to test the contents of the Biochemistry shown in the WEB sites simulating the way students search the internet about Bio subjects. About the sites studied (20), none of them was considered excellent, taking into consideration, confiability, adaptation from Carneiro and Henrique (2009), like: quality of information, objectivity, present time references and media resources. In the concern of accuracy of the information, many mistakes were detected, like: phospholipids, glycolipids found in the cell walls of human beings, fatty acids are straight chain of hydrocarbon ending in a carboxyl group and in a metil group in another extremety, the glycerol_is a carbohydrates of three carbons, concerning those mistakes, teachers and students must be aware of advantages and disadvantages that internet can bring to the teaching learning process and together they can stabblish necessary aims so that favorable proposals don't become anti productive to the process.

Supported by: IFF Campus Campos-Centro. 